\title{
Compliance with Dietary Guidelines and Increased Fortification Can Double Vitamin D Intake: A Simulation Study
}

\author{
Rajwinder K. Harika Mariska Dötsch-Klerk Peter L. Zock Ans Eilander \\ Unilever Research and Development, Vlaardingen, The Netherlands
}

\author{
Key Words \\ Vitamin D · Margarine $\cdot$ Fish $\cdot$ Meat · Milk · Dietary \\ guidelines $\cdot$ Fortification $\cdot$ Simulation
}

\begin{abstract}
Objective: The study aimed to determine the potential of compliance with Food-Based Dietary Guidelines (FBDG) and increased vitamin $D$ fortification to meet the recommended intake level of vitamin $D$ at $10 \mu \mathrm{g} /$ day based on minimal exposure to sunlight. Methods: The main dietary sources of vitamin $D$ were derived from national dietary surveys in adults from United Kingdom (UK) $(n=911)$, Netherlands (NL) $(n=1,526)$, and Sweden (SE) $(n=974)$. The theoretical increase in population vitamin $D$ intake was simulated for the following: (1) compliance with FBDG, (2) increased level of vitamin $\mathrm{D}$ in commonly fortified foods, and (3) combination of both. Results: Median usual vitamin D intake was 2.4 (interquartile range 1.7-3.4) $\mu \mathrm{g} /$ day in UK, 3.4 (2.7-4.2) $\mu \mathrm{g} /$ day in NL, and 5.3 (3.9-7.3) $\mu \mathrm{g} /$ day in SE. The top 3 dietary sources of vitamin D were fish, fat-based spreads (margarines), and meat. Together, these delivered up to two-thirds of total vitamin D intake on average. Compliance with FBDG for fish, margarine, and meat increased vitamin D intake to 4.6 (4.15.1) $\mu \mathrm{g} /$ day in UK, 5.2 (4.9-5.5) $\mu \mathrm{g} /$ day in NL, and 7.7 (7.0-8.5) $\mu \mathrm{g} /$ day in SE. Doubling the vitamin $D$ levels in margarines and milk would increase vitamin D intake to $4.9(3.6-6.5) \mu \mathrm{g} /$ day in UK, $6.6(4.8-8.6) \mu \mathrm{g} /$ day in $\mathrm{NL}$, and $7.2(5.2-9.8) \mu \mathrm{g} /$ day
\end{abstract}

in SE. Combining both scenarios would increase vitamin $D$ intake to 7.9 (6.8-9.2) $\mu \mathrm{g} /$ day in UK, $8.8(7.4-10.4) \mu \mathrm{g} /$ day in $\mathrm{NL}$, and 8.9 (6.9-11.8) $\mu \mathrm{g} /$ day in SE. Conclusion: This study highlights the potential of dietary measures to double the current vitamin D intake in adults. @ 2016 The Author(s)

Published by S. Karger AG, Basel

\section{Introduction}

Vitamin D is a fat-soluble vitamin that plays a vital role in bone health and metabolism. It has also been associated with a large number of non-skeletal health functions, particularly on the immune, endocrine, and cardiovascular systems $[1,2]$. Vitamin D is, strictly speaking, not an essential nutrient as it can be synthesized in the skin by the action of sunlight [3]. However, recent studies show that skin synthesis of vitamin D is insufficient for many people, mainly due to limited sunlight exposure [4]. Therefore, dietary vitamin $\mathrm{D}$ may be more important to achieve an optimal serum 25 -hydroxyvitamin D $(25[\mathrm{OH}] \mathrm{D})$ status in the population than it was previously thought to be [5].

Recently, several European countries have set the recommended intake of vitamin $\mathrm{D}$ (required nutrient intake [RNI]) for adults at $10 \mu \mathrm{g} /$ day $[2,6,7]$ whereas the previous recommendation ranged from 0 to $10 \mu \mathrm{g} /$ day [8]. This recommendation is based on a threshold serum 
$25(\mathrm{OH}) \mathrm{D}$ concentration of $25 \mathrm{nmol} / \mathrm{L}$. This concentration represents a "population protective" level, that is, the $25(\mathrm{OH}) \mathrm{D}$ concentration below which the risk of poor musculoskeletal health is increased and above which the risk is decreased at a population level. The RNI of $10 \mu \mathrm{g} /$ day is based on a situation of minimal exposure to sunshine $[2,6]$.

Only a limited number of commonly consumed foods, such as fatty fish, meat, eggs, mushrooms, and vitamin$\mathrm{D}$-fortified products, contribute to vitamin $\mathrm{D}$ intake in the population $[9,10]$. Therefore, relying on dietary sources alone is not sufficient especially for vulnerable groups with relatively high vitamin $\mathrm{D}$ requirements, such as children $(<4$ years), pregnant and lactating women, and elderly and it is recommended that these groups take daily vitamin D supplements $[2,11]$. Vitamin D supplements are usually not recommended for adults, and indeed supplement use is generally low among European adults [12].

Jenab et al. [13] reported an average intake of $4.1 \mu \mathrm{g} /$ day vitamin D in European countries. With the new recommended vitamin $\mathrm{D}$ intake of $10 \mu \mathrm{g} /$ day, it is evident that a major part of the population will fall short of this intake level. Earlier studies investigated the importance of different dietary sources to population intakes of vitamin $\mathrm{D}[14$, 15], whereas others addressed the potential contribution of fortification of common foods with vitamin D [16-18]. These studies concluded that vitamin D intake was too low to sustain a healthy vitamin D status in the population without mandatory fortification of staple foods or without a dramatic increase in fish consumption.

Food-Based Dietary Guidelines (FBDG) provide advice on foods, food groups, and dietary patterns, which provide the recommended nutrients to promote overall public health and prevent chronic diseases. FBDG that may influence vitamin $\mathrm{D}$ intake are guidelines regarding fish, meat, eggs, and vitamin-D-fortified foods intake. To our knowledge, no study till date has assessed whether compliance with current FBDG would be sufficient to reach the new recommended vitamin $\mathrm{D}$ daily intake of $10 \mu \mathrm{g}$. In addition, few studies have predicted the impact of fortification of common foods on vitamin D intake in different countries. In the present study, we assessed the contribution of different dietary sources to vitamin D intake in adult populations in the Netherlands (NL), the United Kingdom (UK), and Sweden (SE). In addition, we simulated the theoretical impact on population vitamin D intake for (1) compliance with FBDG, (2) doubling the level of vitamin D in commonly fortified foods, and (3) a combination of these 2 scenarios.

Dietary Measures to Increase Vitamin D

\section{Materials and Methods}

Survey Data and Classification of Foods in Food Groups

For this study, individual subject data from the latest national dietary surveys from the NL (Dutch National Food consumption Survey [2007-2010]) [19], the UK (National Diet and Nutrition Survey [2008-2011]) [20], and SE (Riksmaten [2012]) [21] were used. To assess dietary intake, the UK and SE surveys used a 4-day food record method, and the NL used the $2 \times 24$-h dietary recall. To facilitate comparison across intakes from different countries, data analysis was restricted to the adult age group (18-50 years) from the NL $(n=1,526)$, the UK $(n=911)$, and SE $(n=974)$. Data on supplement use were not included in this study as the focus was only on food sources.

To compare the contribution of different food sources to vitamin D intake, 14 comparable food groups were created across the 3 countries. These food groups were the following: meat (including poultry), fish, added fats (fat-based spreads, butter, oils, and others), eggs, dairy (milk, yoghurt, cheese, cream, ice-cream), cereals (breakfast cereals, bread, muesli, oats, rice, pasta, pizza, and sandwiches), confectionery and desserts, savory and sauces, vegetables, fruits, potatoes, legumes and seeds, drinks, and miscellaneous. Each food group's contribution to average daily vitamin D intake was calculated by combining food consumption data from national dietary surveys in each country with their respective national food composition tables.

Simulation of Compliance to FBDG on Vitamin D Intake

For simulating compliance with FBDG for vitamin D intake, we selected the top 3 food groups that according to our analysis contributed the most to vitamin D intake. These included fish, meat, and fatbased spreads (which is a subgroup of the added fats food group). We simulated the intake for meat and fish in line with daily portion sizes as advised by FBDG in these countries [22-24], and as advised for fatbased spreads in the NL [22]. This resulted in simulated amounts of intakes of these foods in the 3 populations as described below:

- Fish: $\geq 2$ portions $(2 \times 140 \mathrm{~g}) /$ week, of which at least one portion from fatty fish (i.e., total $\geq 40 \mathrm{~g}$ fish/day from $\geq 20 \mathrm{~g}$ fatty fish and $\geq 20$ g other fish daily) $[23,24]$,

- Meat: <500 g/week (i.e., <70 g/day) [22-24],

- Fat-based spreads (margarine): $\geq 20$ g/day [22].

The impact of compliance to the FBDG was simulated for the 3 food groups, that is, fish, meat, and fat-based spreads separately, as well as for all 3 together. For each of these food groups, original data on individual intakes were adjusted to intake levels according to recommendations by the FBDG. The intake levels in subjects that already complied with each of the food group's guidelines were left unchanged.

For fish, to simulate compliance with the FBDG intake of at least $40 \mathrm{~g}$ fish/day (of which $20 \mathrm{~g}$ fatty fish), the vitamin $\mathrm{D}$ content of an "average model fish" was estimated for each country. From the surveys, individual intake data for fish were separated into "fatty fish" (i.e., salmon, mackerel, herring, eel, tuna, sardines, trout, pilchards, and kipper) and "other fish" (i.e., cod, sea bass, haddock, plaice, hake, sole, and shellfish). For each country, the mean vitamin D content for both types of fish was calculated, and the "average model fish" was estimated to include half "fatty fish" and half "other fish." The vitamin D content per $100 \mathrm{~g}$ of "average model fish" was $3 \mu \mathrm{g}$ for NL, $2.5 \mu \mathrm{g}$ for UK, and $6 \mu \mathrm{g}$ for SE. Subsequently, we increased the original intakes of subjects consuming 
no or little fish (up to $40 \mathrm{~g}$ of "average model fish"), while the intakes of consumers already complying with the FBDG for fish were left unchanged.

For meat, to simulate compliance according to the FBDG intake of $<70 \mathrm{~g}$ of meat/day, we created an "average model meat" for each country. This "average model meat" provided the average vitamin D content from all different meat varieties consumed during the surveys. The vitamin D content per $100 \mathrm{~g}$ of "average model meat" was $1 \mu \mathrm{g}$ for NL, $0.9 \mu \mathrm{g}$ for $\mathrm{UK}$, and $0.6 \mu \mathrm{g}$ for SE. When original meat intake was higher than $>70 \mathrm{~g} /$ day, intakes were adjusted to $<70 \mathrm{~g} /$ day "average model meat." Intakes of individuals consuming no or little ( $<70 \mathrm{~g} /$ day) meat were left unchanged.

For fat-based spreads, the FBDG from the NL recommends a daily intake of $\sim 20-50 \mathrm{~g}$ of fat-based spreads (margarine) [22]. To simulate the compliance with the FBDG of $20 \mathrm{~g}$ /day of fat-based spreads (margarine), we adjusted the current intake of subjects consuming no or little fat-based spreads to $20 \mathrm{~g} /$ day and left the intake of subjects consuming $>20 \mathrm{~g} /$ day of fat-based spreads unchanged in data from all 3 countries. As "average model margarine," we selected an average vitamin-D-fortified soft spread from the food composition table of each country.

\section{Simulation of Increasing the Level of Vitamin D in Commonly} Fortified Foods on Vitamin D Intake

To simulate the potential impact of increasing the amount of vitamin $\mathrm{D}$ added to food products, we focused solely on margarine and milk. For this scenario, we changed the vitamin D content of milk (skimmed and semi-skimmed milk) and margarine in each of the 3 country's food composition tables to a higher level. For milk, we simulated an increased fortification level of $1 \mu \mathrm{g} / 100 \mathrm{~g}$, which is double the mandatory fortification level of semi-skimmed and skimmed milk ( 0.38-0.5 $\mu \mathrm{g} / 100 \mathrm{~g})$ in SE [25]. In the NL and the UK, there is currently no mandatory fortification of milk and the levels were changed from 0 to $1 \mu \mathrm{g} / 100 \mathrm{~g}$. For margarine, we simulated an increased fortification level of $15 \mu \mathrm{g} / 100 \mathrm{~g}$, which is 1.5-2 times the current vitamin D levels in the NL and the UK (7.5 $\mu \mathrm{g} / 100 \mathrm{~g})[26,27]$ and SE $(7.5-10 \mu \mathrm{g} / 100 \mathrm{~g})$ [25]. We also simulated the change in intake of vitamin $D$ if both milk and margarine would be fortified with these higher levels of vitamin D.

Simulation of Compliance to FBDG and Increasing the Level of Vitamin D in Commonly Fortified Foods on Vitamin D Intake

In the third scenario, we combined the simulation on compliance with FBDG (paragraph 2.2) with that of increased fortification levels (paragraph 2.3).

Data Analysis

Data analyses were performed with DaDiet (version 13.05), which is a web-based dietary intake evaluation tool (www.dazult. com) [28]. Median and interquartile ranges of usual vitamin D were estimated for baseline intake and for the simulated scenarios.

In DaDiet, the Iowa State University Foods (ISUF) model [29] is applied to calculate usual intakes. Usual nutrient intake is the long-run average of daily intake of nutrient or food [29]. In addition, this method allows for varying degrees of deviation from normality and recognizes the measurement error associated with dietary intakes based on a small number of days (e.g., $2 \times 24 \mathrm{~h}$ recall).

When calculating usual intakes, DaDiet calculates the dietary intake of various nutrients for every subject within the survey, as well as recording the food group responsible for intake of the nu-
Table 1. Vitamin D intake in adults (18-50 years) in the NL, the $\mathrm{UK}$, and SE

\begin{tabular}{lcccccc}
\hline \multirow{2}{*}{ Countries } & \multirow{2}{*}{ Sample size } & \multicolumn{5}{c}{ Usual intake of vitamin $\mathrm{D}, \mu \mathrm{g} / \mathrm{day}$} \\
\cline { 3 - 7 } & & P25 & P50 & P75 & mean & SD \\
\hline NL & 1,526 & 2.71 & 3.40 & 4.23 & 3.55 & 1.19 \\
UK & 911 & 1.79 & 2.49 & 3.44 & 2.75 & 1.32 \\
SE & 974 & 3.90 & 5.38 & 7.35 & 5.95 & 2.87 \\
\hline
\end{tabular}

trient. The tool adjusts for each subject's survey weight (variances in sociodemographic characteristics, seasonal and weekday differences) to calculate various statistics, including means and percentiles, for the total population, or sub-populations such as age bands or consumers of certain foods [28].

\section{Cut-Point Method}

The estimated average requirement (EAR) cut-point method provides a way to estimate the prevalence of inadequate nutrient intake in a population. The European countries, that is, the UK, the NL, and SE, only provide RNI and no EAR $[2,6,7]$. The RNI on vitamin $\mathrm{D}$ in these countries corresponds to the EAR of $10 \mu \mathrm{g} / \mathrm{day}$, as defined by the Institute of Medicine (USA) as a benchmark [1]. The proportion of subjects with usual intakes below the EAR was used to estimate the prevalence of inadequate vitamin D intake in the population using the ISUF model [29].

\section{Results}

Usual Intake Levels and Dietary Sources of Vitamin D At baseline, usual median intakes of vitamin $\mathrm{D}$ in the adult population were $2.4(1.7-3.4) \mu \mathrm{g} /$ day in the UK, 3.4 (2.7-4.2) $\mu \mathrm{g} /$ day in the NL, and 5.3 (3.9-7.3) $\mu \mathrm{g} /$ day in SE, which are considerably lower than the recommended 10 $\mu \mathrm{g} /$ day (Table 1). The data indicate that $0 \%$ of the study population in the UK and the NL and 9\% in SE are estimated to meet the recommended level for vitamin $\mathrm{D}$ intake from diet alone.

The 3 main dietary sources of vitamin $\mathrm{D}$, together contributing up to two-thirds of total vitamin $\mathrm{D}$ intake in these populations, were fish, meat, and added fats (mainly fat-based spreads or margarine fortified with vitamin D). The contribution of fish to vitamin D intake was $14 \%$ in the NL, $26 \%$ in the UK, and 38\% in SE. Contribution of meat to vitamin D intake was $22 \%$ in the NL, $26 \%$ in the UK and $12 \%$ in the SE; and the contribution of added fats (mainly fat-based spreads or margarine) was $40 \%$ in the NL, $19 \%$ in the UK, and $13 \%$ in SE (Table 2). Of the total vitamin $\mathrm{D}$ intake, the fourth most important source of vitamin D was dairy (mainly fortified milk) contribut- 


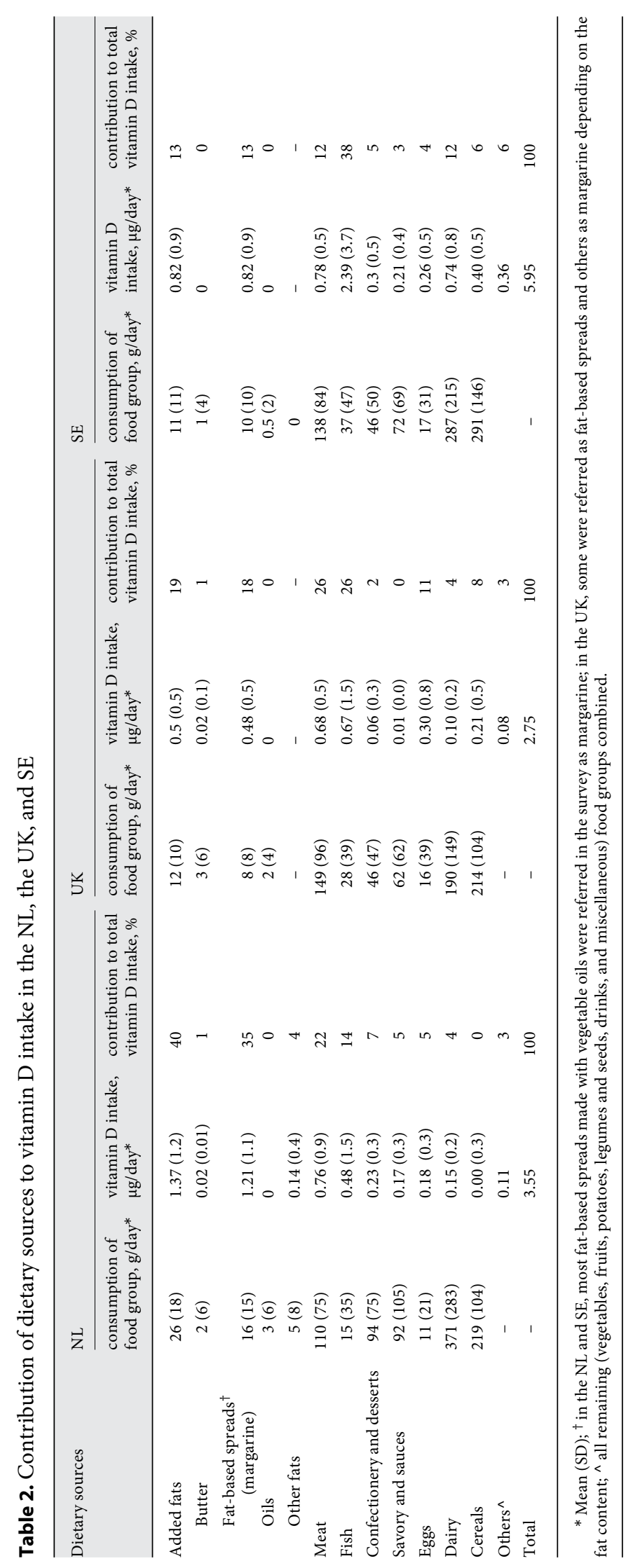

Dietary Measures to Increase Vitamin D ing $12 \%$ in SE, eggs contributing $11 \%$ in the UK, and confectionery and desserts contributing $7 \%$ in the NL. Cereals (mainly fortified breakfast cereals) were the fifth most important source of vitamin D in the UK (8\%) and in SE (6\%). The remaining food groups, that is, vegetables, fruits, potatoes, legumes and seeds, drinks, and miscellaneous, did not substantially contribute to vitamin $\mathrm{D}$ intake and were clustered as "others" (Table 2).

The food groups contributing to vitamin $\mathrm{D}$ intake in the $9 \%$ of the Swedish population meeting the recommended intake level were the same as in the general population. However, the contribution of fish to vitamin D intake was much higher ( $>50 \%$ of total vitamin D intake).

\section{Simulation of Compliance with FBDG on \\ Vitamin D Intake}

In the scenario on fish intake levels compliant with FBDG, median intake of vitamin D increased to 4.3 (3.75.0) $\mu \mathrm{g} /$ day for the NL, $3.4(2.8-4.2) \mu \mathrm{g} /$ day for the UK, and $6.8(5.7-7.9) \mu \mathrm{g} /$ day for SE. In the scenario on fatbased spreads (margarine) intake being compliant with FBDG, the median intake of vitamin D increased to 4.4 $(4.0-4.9) \mu \mathrm{g} / \mathrm{day}$ for the NL, 3.8 (3.1-4.7) $\mu \mathrm{g} /$ day for the $\mathrm{UK}$, and $6.7(5.3-8.6) \mu \mathrm{g} /$ day for SE. In the scenario of meat intake being compliant with FBDG, the median intake of vitamin $\mathrm{D}$ decreased to $2.3(1.6-3.3) \mu \mathrm{g} /$ day for the UK, $3.1(2.4-4.0) \mu \mathrm{g} /$ day for the NL, and 4.9 (3.5-6.7) $\mu \mathrm{g} /$ day for SE. In the scenario of fish, meat, and fat-based spreads (margarine) intake being compliant with FBDG, the median intake of vitamin D increased to 4.6 (4.15.1) $\mu \mathrm{g} /$ day for the UK, $5.2(4.9-5.5) \mu \mathrm{g} /$ day for the NL, and $7.7(7.0-8.5) \mu \mathrm{g} /$ day for SE (Fig. 1). In this scenario of 3 FBDGs, the percentage of population meeting the recommended vitamin D intake increased from 9 to $12 \%$ in SE, while no change was seen in the UK and the NL (Fig. 1).

\section{Simulation of Increasing the Level of Vitamin D in Common Fortified Foods on Vitamin D Intake}

In the scenario of a higher vitamin $\mathrm{D}$ fortification level in margarine $(15 \mu \mathrm{g} / 100 \mathrm{~g})$, median intake of vitamin $\mathrm{D}$ increased to $3.2(2.2-4.4) \mu \mathrm{g} /$ day in the UK, $4.5(3.4-5.9)$ $\mu \mathrm{g} /$ day in the NL, and $5.9(4.3-8.2) \mu \mathrm{g} /$ day in SE (Fig. 2). In the scenario of a higher fortification level of vitamin $\mathrm{D}$ in milk $(1 \mu \mathrm{g} / 100 \mathrm{~mL})$, median intake of vitamin $\mathrm{D}$ increased to $3.3(2.3-4.5) \mu \mathrm{g} /$ day in the UK, 4.9 (3.6-6.4) $\mu \mathrm{g} /$ day in the NL, and $5.9(4.3-8.2) \mu \mathrm{g} /$ day in SE. In the scenario, simulating increased levels of vitamin $\mathrm{D}$ in both milk and margarine, median intake of vitamin $\mathrm{D}$ increased to $4.9(3.6-6.5) \mu \mathrm{g} /$ day in the UK, $6.6(4.8-8.6) \mu \mathrm{g} /$ day in the NL, and 7.2 (5.2-9.8) $\mu \mathrm{g} /$ day in SE (Fig. 2). With the 
$\mathrm{NL}$

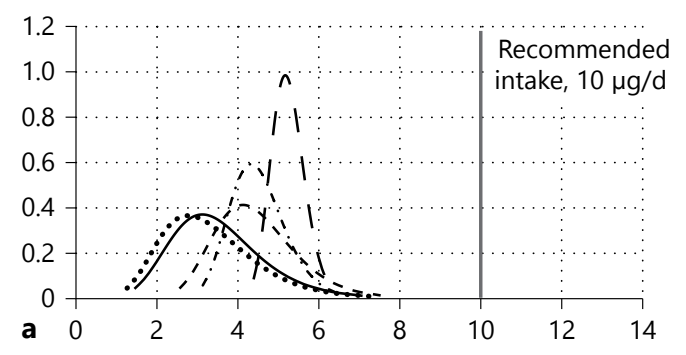

SE

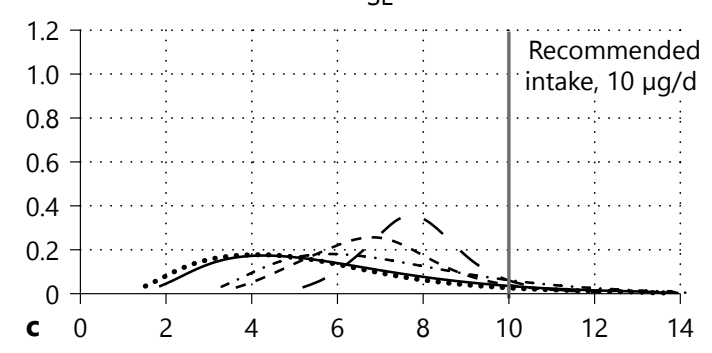

UK

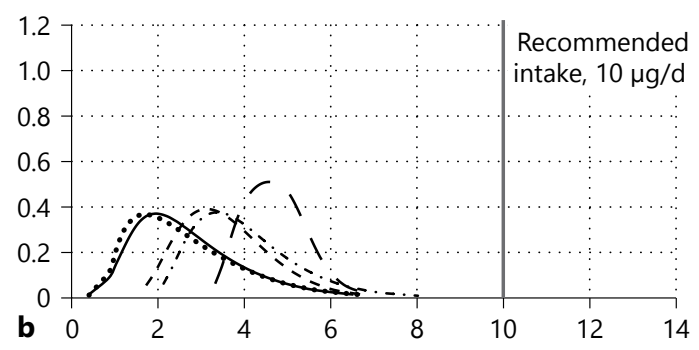

- Original intake

- . - $40 \mathrm{~g}$ fish intake

....... $<70 \mathrm{~g}$ meat

-.... $20 \mathrm{~g}$ margarine

_ _ All 3 food based dietary guidelines

Fig. 1. a-c Simulation of complying with food-based dietary guidelines (on fish, meat, and fat-based spreads [margarine]) on vitamin D intake in the NL, the UK, and SE.

$\mathrm{NL}$

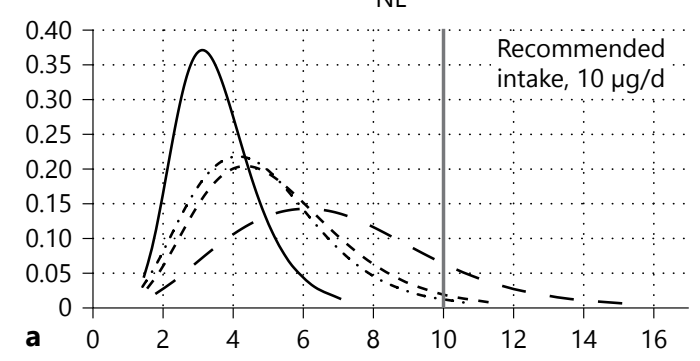

UK

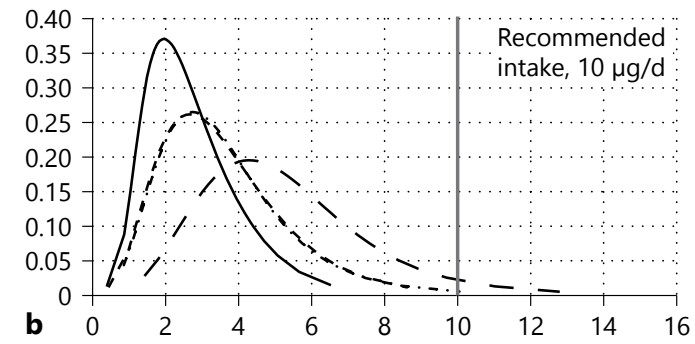

SE

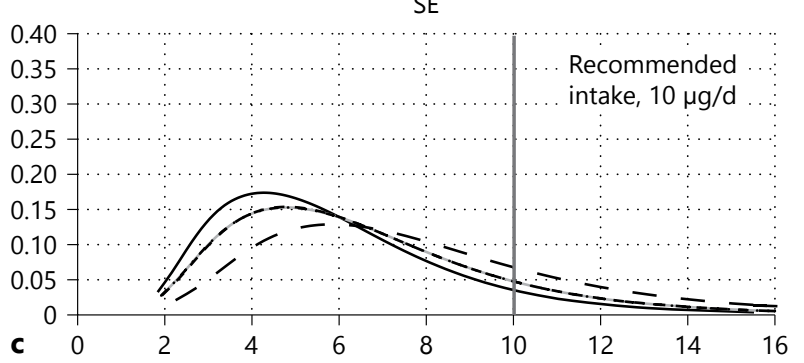

- Original intake

- - - - Fortified milk

-...... Fortified margarine

- - Both fortified

Fig. 2. a-c Simulation of increased level of vitamin D in milk and margarine on vitamin D intake in the NL, the UK, and SE. 


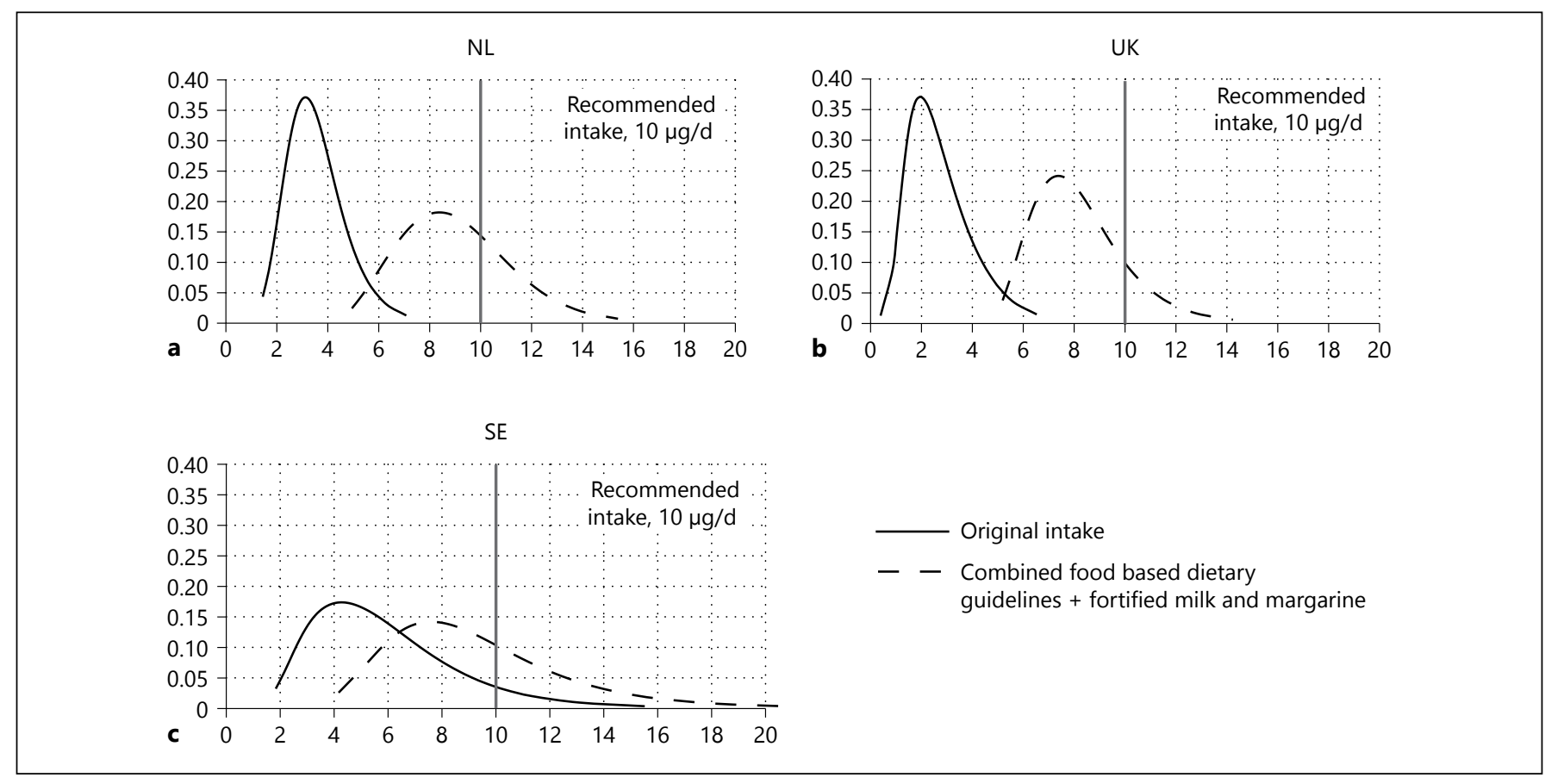

Fig. 3. a-c Simulation of compliance to food-based dietary guidelines and increasing the level of vitamin D in milk and margarine on vitamin $\mathrm{D}$ intake in the NL, the UK, and SE.

increased fortification of both milk and margarine, the percentage of populations meeting the recommended intake for vitamin D increased from 0 to $5 \%$ in the UK, from 0 to $15 \%$ in the NL, and from 9 to $25 \%$ in SE.

\section{Simulation of Compliance to FBDG Combined with}

Increased Vitamin D Levels in Commonly Fortified

Foods on Vitamin D Intake

In the combined scenario of compliance with FBDG and higher vitamin $\mathrm{D}$ fortification levels in margarine and milk, the intake of vitamin D increased to 7.9 (6.89.2) $\mu \mathrm{g} /$ day in the UK, $8.8(7.4-10.4) \mu \mathrm{g} /$ day in the $\mathrm{NL}$, and to $8.9(6.9-11.0) \mu \mathrm{g} /$ day in SE (Fig. 3). With this combined scenario, the percentage of populations meeting the recommended intake increased from 0 to $16 \%$ in the $\mathrm{UK}$, from 0 to $31 \%$ in the NL, and from 9 to $35 \%$ in SE.

\section{Discussion}

Median population intakes of vitamin $\mathrm{D}$ in the NL, the $\mathrm{UK}$, and SE are considerably lower than the recommended intake of $10 \mu \mathrm{g} /$ day. Our analysis shows that the main dietary sources of vitamin $\mathrm{D}$ in these countries are fish, fatbased spreads (margarine), and meat. Together, these food groups contribute up to two-thirds of the total vitamin D intake in the adult population. The scenarios in which we assumed full compliance to FBDG or increased levels of vitamin $\mathrm{D}$ in commonly fortified foods indicate potential strategies to increase the population's vitamin $\mathrm{D}$ intake to $\sim 4-5 \mu \mathrm{g} /$ day in the UK, $\sim 5-6 \mu \mathrm{g} /$ day in the NL, and $\sim 7-8$ $\mu \mathrm{g} /$ day in SE. Combining both scenarios would more than double the current vitamin D intake to $7.9 \mu \mathrm{g} /$ day for the UK and to $8.8 \mu \mathrm{g} /$ day for the NL, while increasing it to 8.9 $\mu \mathrm{g} /$ day for SE. As a result, $35 \%$ of the population in SE, $31 \%$ in the $\mathrm{NL}$, and $16 \%$ in the UK would meet the recommended intake of vitamin D. Although these intakes are insufficient to reach the recommended $10 \mu \mathrm{g} /$ day, these dietary measures have the potential to substantially increase the vitamin $\mathrm{D}$ intake in the general population.

To our knowledge, this study is the first to simulate the potential impact of compliance to FBDG and increased vitamin $\mathrm{D}$ levels in fortified foods (milk and margarine) on vitamin $\mathrm{D}$ intake in 3 countries. This study highlights that complying with dietary guidelines alone or fortifying (increasing) vitamin $\mathrm{D}$ in a limited number of food products will not be sufficient to meet the recommended vitamin D intake level of $10 \mu \mathrm{g} /$ day in the general population. The strength of our study is that it is based on complete nationally representative dietary surveys. In addition, the 
food groups with the highest impact on vitamin D intake in general populations in these surveys were selected for simulating compliance with FBDG. However, several limitations need to be taken into account when interpreting the results. First, the food composition tables used may not be up to date with the most recent data of vitamin D levels in fortified foods [30], and therefore, the contribution of some fortified foods may be slightly underestimated. In addition, the vitamin $\mathrm{D}$ values for the same foods (e.g., salmon) vary substantially between the national food compositions databases from each country. Thus, calculated vitamin D intakes, and in particular for the scenarios with increased fish intake, may not accurately reflect true impact. In addition, a $2 \times 24 \mathrm{~h}$ dietary recall (NL) or even 4-day dietary data collection (UK and SE) may not reliably reflect true vitamin D intake, as these do not accurately reflect intakes of foods that are consumed less frequently, such as fish. However, in all the 3 countries, the dietary recalls were sampled on different days of the week, covering all seasons of the year. Therefore, the fish intakes are representative for the fish consumption in the 3 populations. Moreover, our data on fish consumption are largely in agreement with data from the European Investigation into Cancer and Nutrition Intervention [31]. Therefore, we believe that our data on vitamin $\mathrm{D}$ intake from fish consumption are reasonably representative for the 3 countries.

Second, we did not control for under-reporting which is a general limitation of dietary surveys $[32,33]$. However, vitamin $\mathrm{D}$ is generally not present in snack foods or desserts, which are known to be more susceptible to misreporting than meat, fish, or dairy foods. Nevertheless, the actual contribution to vitamin $D$ intake especially from fatbased spreads may be higher than estimated in our study.

Third, we simulated the vitamin D intake for the total adult study population consuming fish and fat-based spreads without taking into account the fact that some surveyed individuals will be vegetarians, vegans, or nonusers of fat-based spreads. This may overestimate the potential of the combined scenarios to increase population vitamin D intake.

Finally, as the focus of this study was on vitamin D intake from food sources only, the impact on vitamin D status of sun exposure and the intake of vitamin D supplements were not taken into account. Therefore, we cannot conclude that the low vitamin D intake resulted in cases of vitamin $\mathrm{D}$ deficiency.

Fatty fish is the richest natural dietary source of vitamin $\mathrm{D}$ and reported to be a major food contributor to vitamin D intake [13]. In line with this, we found that the higher consumption of (fatty) fish in SE contributed substantially more to vitamin D intake compared to the UK and the NL. Simulating fish intake according to the guidelines ( $40 \mathrm{~g} /$ day) resulted in a relatively small contribution to vitamin D intake ( $10-15 \%$ of the recommended intake) that would not be sufficient to reach the recommended intake of $10 \mu \mathrm{g} /$ day. Similarly, a recent metaanalysis on the potential of fish to improve serum vitamin $\mathrm{D}$ status concluded that fish consumption $(\sim 42 \mathrm{~g} /$ day over 4 weeks) increased the concentration of $25(\mathrm{OH}) \mathrm{D}$, but it was not enough to achieve an optimal vitamin $\mathrm{D}$ status [15]. Thus, to attain higher intakes of vitamin D, it is necessary to consume fatty fish more than once per week. However, at the same time, it must be taken into account that increasing (fatty) fish consumption may have adverse environmental effects [34]. Due to environmental concerns, recently, the NL has changed the guidelines for fish intake to one portion of fish per week [22]. Compliance to this revised guideline would increase vitamin D intake slightly from the current 3.4 to $3.8 \mu \mathrm{g} / \mathrm{day}$ compared to $4.3 \mu \mathrm{g} / \mathrm{day}$ (as shown in our analysis) with the previous NL FBDG of 2 portions of fish per week.

Although meat is less rich in vitamin D than fatty fish, recent data have indicated the presence of $25(\mathrm{OH}) \mathrm{D}$, the metabolized form of vitamin $\mathrm{D}$, in animal-based food products (especially meat, poultry, and eggs) [35]. Thus, the contribution of meat to vitamin $\mathrm{D}$ intake and status could be higher than currently estimated. Taylor et al. [36] have suggested that an additional 1.7-2.9 $\mu \mathrm{g}$ or 15$30 \%$ of the EAR for vitamin D could be added to currently estimated intakes in the US if the presence of $25(\mathrm{OH})$ $\mathrm{D}$ in animal-based foods is taken into account. Nonetheless, due to the increased risk of chronic diseases, the recommendation is to keep intake of meat below $500 \mathrm{~g} / \mathrm{week}$ $[37,38]$. This implies that when following the FBDG, meat cannot contribute more than $5-10 \%$ of the recommended vitamin D intake (based on current information from food composition tables). Because other natural dietary sources of vitamin $\mathrm{D}$, such as mushrooms and egg yolks, contain lower concentrations of vitamin D [30] (Table 2), it is difficult to reach the vitamin D recommendation of $10 \mu \mathrm{g} /$ day with only natural dietary sources. This indicates the need for fortification of common foods with vitamin $\mathrm{D}$, as also suggested by others [37].

Fat-based spreads (margarine) are routinely fortified with vitamin $D$ and thus substantially contribute to the daily intake of vitamin D (up to $35 \%$ ) in each of the 3 countries studied. FBDG on added fats recommend using soft fatbased spreads and oils instead of hard fats and animal fats $[23,24]$, but do not specify a recommended daily amount. 
Therefore, for our simulation on fat-based spreads, we used $20 \mathrm{~g}$ as the recommended portion size which is on the lower end of the FBDG for spreads intake in the NL [22]. Our simulation shows that margarine consumption at a level of $20 \mathrm{~g} /$ day could increase the average population intake of vitamin D by 1.0-1.4 $\mu \mathrm{g} /$ day (10-15\% of the Recommended Dietary Allowance). This is in line with observations in a NL cohort study, where the risk of vitamin $\mathrm{D}$ inadequacy (measured as serum $25[\mathrm{OH}] \mathrm{D}<50 \mathrm{nmol} / \mathrm{L}$ ) was lower (OR $0.41 ; 95 \%$ CI $0.20-0.86$ ) in subjects consuming $\geq 20$ g margarine per day as compared with those who consumed little ( $<20 \mathrm{~g} /$ day) or no margarine [38].

Fortified milk can also contribute to vitamin D intake. At present, it is mandatory in SE to fortify milk with vita$\min \mathrm{D}(0.38-0.5 \mu \mathrm{g} / 100 \mathrm{~mL})$ [25], whereas milk is not routinely fortified in the NL and the UK $[2,6]$. With more than $70 \%$ of the population in the NL, the UK, and SE consuming milk, there is a large potential for increasing vitamin D intake through fortification of milk. Therefore, we also simulated the scenario of fortifying milk with $1 \mu \mathrm{g} / 100 \mathrm{~mL}$ vitamin $\mathrm{D}$ for all 3 countries, which is twice the level of vitamin D fortification currently used in SE. The increase in vitamin D intake by milk fortification ranged from $\sim 0.6$ to $1.5 \mu \mathrm{g} /$ day, reflecting the differences between the countries in amounts of milk consumed. A model study in a Canadian population showed that fortification of milk, yogurt, and cheese at $6.75 \mu \mathrm{g} / \mathrm{serving}$ could more than double the intake of vitamin $\mathrm{D}$ across all sex and age groups, resulting in a decrease in the prevalence of vitamin $\mathrm{D}$ inadequacy from $>80$ to $<50 \%$ [39]. A much higher level of vitamin D used for milk fortification and other dairy products may explain the greater impact of milk fortification in Canada as compared to our findings. A recent review by Cashman and Kiely [40] concluded that relying on a single staple, that is, fortification of dairy products with vitamin D, might not be enough to prevent inadequate vitamin $\mathrm{D}$ intakes in the entire population.

Our simulation showed that fortifying both margarine and milk with higher levels of vitamin D is more effective than fortification of either milk or margarine alone. In a model study in the Danish population, Rasmussen et al. [41] also assessed the potential effectiveness of fortification of milk, fat-based spreads, and a combination of these foods to increase the vitamin D intake. They concluded that the combined fortification of milk $(1.1 \mu \mathrm{g} / 100 \mathrm{~g})$ and fat-based spreads $(9.5 \mu \mathrm{g} / 100 \mathrm{~g})$ would be an effective strategy for increasing current vitamin $D$ intake in the population, without increasing the risk of people exceeding the safe upper levels for vitamin D. However, both this and our study show that these combined measures would

Dietary Measures to Increase Vitamin D not be sufficient to reach the recommended vitamin $\mathrm{D}$ intake of $10 \mu \mathrm{g} /$ day in the entire population.

These findings are also in line with data from national surveys and studies conducted in Canada and Finland, which show that, despite widespread fortification of milk and margarine, vitamin D intake is still lower than the recommended intake $[42,43]$. We estimated that to obtain a median population intake of $10 \mu \mathrm{g} /$ day for vitamin $\mathrm{D}$ at current intakes of margarine (e.g., in the NL population), margarine would need to contain $\sim 25 \mu \mathrm{g} / 100 \mathrm{~g}$ of vitamin $\mathrm{D}$, which is 3.5 -fold the current level. Milk would need to contain $3 \mu \mathrm{g} / 100 \mathrm{~mL}$, which is 6-fold the current level practiced in SE. Such high levels may currently not be feasible because of limits for food fortification set by food regulations and law. In addition, we did not simulate to what extent higher levels of fortification would affect vitamin $\mathrm{D}$ intake in vulnerable population subgroups, such as children, elderly subjects, and ethnic groups. As children consume more milk than older population groups and some ethnic groups are less likely to consume spreads [44], the impact of fortification on vitamin D intake may respectively be higher and lower than in the general population. Thus, a large part of the adult population that does not consume any or little milk and margarine (up to $30 \%$ of the population, according to our analysis) would not benefit from the increased levels of vitamin D in these food products.

Our simulation of compliance with FBDG combined with increased fortification of milk and margarine shows the potential to increase the population median vitamin $\mathrm{D}$ intake in these 3 countries to approximately $8 \mu \mathrm{g} /$ day. This is more than double the current intakes in the UK and the NL. However, it is estimated that with the combined scenarios more than $65 \%$ of the population in SE, $69 \%$ in the NL, and $84 \%$ in the UK would still fail to meet the recommended vitamin D intake of $10 \mu \mathrm{g} /$ day. Additional public health strategies will be needed to further increase vitamin D intakes. Fortification of other commonly consumed foods such as oils or flour [18] and biofortification of natural sources such as fish, meat, and eggs with vitamin $\mathrm{D}$ could be considered as options to increase population intakes of vitamin D [45].

\section{Conclusion}

Vitamin D intake in the adult populations of the UK, the NL, and SE are considerably lower than the recommended daily intake of $10 \mu \mathrm{g}$, which is based on minimal exposure to sunlight. In these countries, fish, meat, and 
fat-based spreads (margarine) are the top 3 dietary sources of vitamin D. Consumption of fish, meat, and margarine at levels recommended in the FBDG alone seems insufficient to reach the recommended daily intake level of vitamin D. Increased fortification of margarine and milk with vitamin $\mathrm{D}$ could increase population vitamin $\mathrm{D}$ intake, but higher amounts of vitamin $\mathrm{D}$ would need to be added to have a substantial impact on population intakes. Compliance with FBDG combined with increased fortification of margarine and milk has the potential to more than double vitamin D intakes in the UK and the NL, and would bring median intakes closer to the recommended $10 \mu \mathrm{g} /$ day in the 3 countries studied. However, effective public health strategies and fortification of more foods would be needed to increase population intakes of vitamin $\mathrm{D}$ to the recommended level of 10 $\mu \mathrm{g} /$ day.

\section{Author Contributions}

R.K.H. was responsible for the study concept and design, dataanalysis and interpretation, and writing of the manuscript. A.E. and M.D.-K. contributed to study design, methods, interpretation of the data, and writing of the manuscript. P.L.Z. contributed to interpretation of the data and writing of the manuscript. All authors have read and approved the final manuscript.

\section{Disclosure Statement}

All the authors are employees of Unilever. Unilever markets food products including margarines.

\section{Financial Disclosure}

All authors are employed by Unilever.

\section{References}

1 IOM: Dietary Reference Intakes for Calcium $\$ 10$ Holden JM, Lemar LE: Assessing vitamin D and Vitamin D. Washington, Institute of Medicine Food and Nutrition Board, 2011.

2 Scientific Advisory Committee on Nutrition: Draft Vitamin D and Health Report: Scientific Consultation: 22 July to 23 September, 2015.

3 Holick MF, MacLaughlin JA, Clark MB, Holick SA, Potts JT Jr, Anderson RR, Blank IH, Parrish JA, Elias P: Photosynthesis of previtamin D3 in human skin and the physiologic consequences. Science 1980;210:203-205.

-4 Ashwell M, Stone EM, Stolte H, Cashman KD, Macdonald H, Lanham-New S, Hiom S, Webb A, Fraser D: UK Food Standards Agency Workshop Report: an investigation of the relative contributions of diet and sunlight to vitamin D status. Br J Nutr 2010;104:603-611.

$\checkmark 5$ Cashman KD, Kiely M: Recommended dietary intakes for vitamin $\mathrm{D}$ : where do they come from, what do they achieve and how can we meet them? J Hum Nutr Diet 2014;27:434442.

6 Health Council of the Netherlands: Evaluation of Dietary Reference Values for Vitamin D. The Hague, Health Council of the Netherlands, 2012.

7 Norden: Nordic Nutrition Recommendations 2012: Integrating Nutrition and Physical Activity. Copenhagen, Nordic Council of Ministers, 2012.

8 Commission of the European Communities: Nutrient and Energy Intakes for the European Community. Reports of the Scientific Committee for Food. Luxembourg, Office for Official Publications of the European Communities, 31st series, 1993.

-9 Lamberg-Allardt C: Vitamin D in foods and as supplements. Prog Biophys Mol Biol 2006; 92:33-38. contents in foods and supplements: challenges and needs. Am J Clin Nutr 2008;88:551S$553 S$.

$\$ 11$ Balvers MG, Brouwer-Brolsma EM, Endenburg S, de Groot LC, Kok FJ, Gunnewiek JK: Recommended intakes of vitamin D to optimise health, associated circulating 25-hydroxyvitamin D concentrations, and dosing regimens to treat deficiency: workshop report and overview of current literature. J Nutr Sci 2015;4:e23.

12 Bates B, Lennox A, Bates C, Swan G: National Diet and Nutrition Survey: Headline Results from Years 1 and 2 (Combined) of the Rolling Programme (2008/2009-2009/2010), 2012.

13 Jenab M, Salvini S, van Gils CH, Brustad M, Shakya-Shrestha S, Buijsse B, Verhagen H, Touvier M, Biessy C, Wallstrom P, et al: Dietary intakes of retinol, beta-carotene, vitamin $D$ and vitamin $E$ in the European Prospective Investigation into Cancer and Nutrition cohort. Eur J Clin Nutr 2009; 63(suppl 4):S150-S178.

14 Black LJ, Walton J, Flynn A, Kiely M: Adequacy of vitamin D intakes in children and teenagers from the base diet, fortified foods and supplements. Public Health Nutr 2013;17: $721-731$.

15 Lehmann U, Gjessing HR, Hirche F, MuellerBelecke A, Gudbrandsen OA, Ueland PM, Mellgren G, Lauritzen L, Lindqvist H, Hansen $A L$, et al: Efficacy of fish intake on vitamin D status: a meta-analysis of randomized controlled trials. Am J Clin Nutr 2015;102:837847.

16 Laaksi IT, Ruohola JP, Ylikomi TJ, Auvinen A, Haataja RI, Pihlajamaki HK, Tuohimaa PJ:
Vitamin D fortification as public health policy: significant improvement in vitamin D status in young Finnish men. Eur J Clin Nutr 2006;60:1035-1038.

17 Black LJ, Seamans KM, Cashman KD, Kiely M: An updated systematic review and metaanalysis of the efficacy of vitamin D food fortification. J Nutr 2012;142:1102-1108.

18 Allen RE, Dangour AD, Tedstone AE, Chalabi Z: Does fortification of staple foods improve vitamin $D$ intakes and status of groups at risk of deficiency? A United Kingdom modeling study. Am J Clin Nutr 2015;102: 338-344.

19 Dutch National Food Consumption Survey: DNFCS Core Survey 2007-2010.

20 National Diet and Nutrition Survey Years 1-3, 2008-2011. UK Data Services. http:// dx.doi.org/10.5255/UKDA-SN-6533-6.

21 Riksmaten - vuxna 2010-11 Livsmedels- och näringsintag bland vuxna i Sverige. National Diet and Nutrition Survey of Sweden, 20102011. http://www.slv.se/sv/grupp1/Mat-ochnaring/Matvanor--undersokningar/.

22 Richtlijnen Schijf van Vijf. http://www.voedingscentrum.nl/Assets/Uploads/voedingscentrum/Documents/Consumenten/ Schijf\%20van\%20Vijf\%202016/VC_Richtlijnen_Schijf_van_Vijf_2016.pdf.

23 Livsmedelsverket: Swedish dietary Guidelines. www.livsmedelsverket.se.

24 The Eatwell Guide. https://www.food.gov.uk/ sites/default/files/finaleatwellguide23mar2016nothernireland23rd.pdf.

25 Agency TSF: SLVFS 1983:2. Livsmedelsverkets föreskrifter om berikning av vissa livsmedel. (SLVFS 1983:2). The Swedish Food Agency's Legislation Regarding Fortification of Certain Foods), 2007. 
26 MVO: Warenwetbesluit Toevoeging MicroVoedingsstoffen aan Levensmiddelen: Article 5a - Max Vitamin D Levels in Spreads Are 0.075 Microgram Per Gram, 2015.

27 The Spreadable Fats (Marketing Standards) and the Milk and Milk Products (Protection of Designations) (England) Regulations 2008. No. 1287. http://www.legislation.gov.uk/ uksi/2008/1287/regulation/4/made.

28 Dietary Intake Evaluation Tool, version 13.5. http://dadiet.daanalysis.com/info/.

29 Nusser SM, Fuller WA, Guenther PM: Estimation of usual dietary intake distributions: adjusting for measurement error and nonnormality in 24-hour food intake data; in Trewin D (ed): Survey Measurement and Process Quality. New York, Wiley, 1996, pp 689-709.

30 Byrdwell WC, Devries J, Exler J, Harnly JM Holden JM, Holick MF, Hollis BW, Horst RL, Lada M, Lemar LE, et al: Analyzing vitamin D in foods and supplements: methodologic challenges. Am J Clin Nutr 2008;88:554S-557S.

- 31 Welch AA, Lund E, Amiano P, Dorronsoro M, Brustad M, Kumle M, Rodriguez M, Lasheras C, Janzon L, Jansson J, et al: Variability of fish consumption within the 10 European countries participating in the European Investigation into Cancer and Nutrition (EPIC) study. Public Health Nutr 2002;5 1273-1285.

32 Black AE, Prentice AM, Goldberg GR, Jebb SA, Bingham SA, Livingstone MB, Coward WA: Measurements of total energy expendi- ture provide insights into the validity of dietary measurements of energy intake. J Am Diet Assoc 1993;93:572-579.

33 Livingstone MB, Prentice AM, Strain JJ, Coward WA, Black AE, Barker ME, McKenna PG, Whitehead RG: Accuracy of weighed dietary records in studies of diet and health. BMJ 1990;300:708-712.

- 34 Sirot V, Leblanc JC, Margaritis I: A risk-benefit analysis approach to seafood intake to determine optimal consumption. Br J Nutr 2012;107:1812-1822.

35 Clausen I, Jakobsen J, Leth T, Ovesen L: Vitamin D3 and 25-hydroxyvitamin D3 in raw and cooked pork cuts. J Food Comp Anal 2003; 16:575-585.

36 Taylor CL, Patterson KY, Roseland JM, Wise SA, Merkel JM, Pehrsson PR, Yetley EA: Including food 25 -hydroxyvitamin $\mathrm{D}$ in intake estimates may reduce the discrepancy between dietary and serum measures of vitamin D status. J Nutr 2014;144:654-659.

37 O’Donnell S, Cranney A, Horsley T, Weiler HA, Atkinson SA, Hanley DA, Ooi DS, Ward L, Barrowman N, Fang M, et al: Efficacy of food fortification on serum 25-hydroxyvitamin D concentrations: systematic review. Am J Clin Nutr 2008;88:1528-1534.

38 van Dam RM, Snijder MB, Dekker JM, Stehouwer CD, Bouter LM, Heine RJ, Lips P: Potentially modifiable determinants of vitamin D status in an older population in the Netherlands: the Hoorn study. Am J Clin Nutr 2007;85:755-761.
39 Shakur YA, Lou W, L'Abbe MR: Examining the effects of increased vitamin $D$ fortification on dietary inadequacy in Canada. Can J Public Health 2014;105:e127-e132.

40 Cashman KD, Kiely M: Tackling inadequate vitamin $\mathrm{D}$ intakes within the population: fortification of dairy products with vitamin $\mathrm{D}$ may not be enough. Endocrine 2016;51:38-46.

41 Rasmussen LB, Hansen GL, Hansen E, Koch B, Mosekilde L, Molgaard C, Sorensen $\mathrm{OH}$, Ovesen L: Vitamin D: should the supply in the Danish population be increased? Int J Food Sci Nutr 2000;51:209-215.

42 Pietinen P, Paturi M, Reinivuo H, Tapanainen H, Valsta LM: FINDIET 2007 Survey: energy and nutrient intakes. Public Health Nutr 2010;13:920-924.

43 Whiting SJ, Langlois KA, Vatanparast $\mathrm{H}$, Greene-Finestone LS: The vitamin D status of Canadians relative to the 2011 Dietary Reference Intakes: an examination in children and adults with and without supplement use. Am J Clin Nutr 2011;94:128-135.

44 Wijsman-Grootendorst A, van Dam RM: [The attitude of Dutch women of Turkish ancestry towards measures for the prevention and treatment of vitamin D deficiency; the results of focus group interviews]. Ned Tijdschr Geneeskd 2005;149:932-936.

45 Cashman K, Duffy S, Hayes A, Seamans K, Kerry J, Kelly A, Jakobsen J, O’Doherty J: Biofortification of eggs and pork with vitamin D as a means of increasing dietary supply. FASEB J 2015;29(suppl 1);758-813. 